AperTO - Archivio Istituzionale Open Access dell'Università di Torino

\title{
Costly voting, turnout, and candidate valence
}

\section{This is a pre print version of the following article:}

Original Citation:

Availability:

This version is available http://hdl.handle.net/2318/1644061

since 2018-03-20T18:07:47Z

Published version:

DOI:10.1016/j.econlet.2017.06.025

Terms of use:

Open Access

Anyone can freely access the full text of works made available as "Open Access". Works made available under a Creative Commons license can be used according to the terms and conditions of said license. Use of all other works requires consent of the right holder (author or publisher) if not exempted from copyright protection by the applicable law. 
This Accepted Author Manuscript (AAM) is copyrighted and published by Elsevier. It is posted here by agreement between Elsevier and the University of Turin. Changes resulting from the publishing process - such as editing, corrections, structural formatting, and other quality control mechanisms - may not be reflected in this version of the text. The definitive version of the text was subsequently published in ECONOMICS LETTERS, 158, 2017, 10.1016/j.econlet.2017.06.025.

You may download, copy and otherwise use the AAM for non-commercial purposes provided that your license is limited by the following restrictions:

(1) You may use this AAM for non-commercial purposes only under the terms of the CC-BY-NC-ND license.

(2) The integrity of the work and identification of the author, copyright owner, and publisher must be preserved in any copy.

(3) You must attribute this AAM in the following format: Creative Commons BY-NC-ND license (http://creativecommons.org/licenses/by-nc-nd/4.0/deed.en), 10.1016/j.econlet.2017.06.025

The publisher's version is available at:

http://linkinghub.elsevier.com/retrieve/pii/S0165176517302525

When citing, please refer to the published version.

Link to this full text:

http://hdl.handle.net/2318/1644061 


\title{
Costly voting, turnout, and candidate valence
}

\author{
Anna Lo Prete * \\ Federico Revelli **
}

June, 2017

\begin{abstract}
We build a model of voluntary and costly expressive voting, where the relative weight of ideology and valence issues over voting costs determines how people vote and if they actually turn out to vote. In line with the conventional rational calculus approach, the model predicts that the cost of voting depresses voter turnout. Against the conventional wisdom, though, high voting cost/low turnout elections tend to have a larger share of voters for whom the common value signal on candidates' valence matches their private value views, thus raising the chances that high valence candidates are elected.
\end{abstract}

JEL classification: D72; H70.

Key words: voter turnout; voting cost; ideology; valence.

\footnotetext{
* Department of Economics and Statistics, University of Torino, Campus Luigi Einaudi, Lungo Dora Siena 100A, 10153 Turin (Italy), and CeRP - Collegio Carlo Alberto; email: anna.loprete@unito.it.

** Corresponding author. Department of Economics and Statistics, University of Torino, Campus Luigi Einaudi, Lungo Dora Siena 100A, 10153 Turin (Italy); e-mail: federico.revelli@unito.it.

*** We would like to thank seminar participants in Ancona, Lugano (IIPF2014 Congress), Milan (Political Economy Workshop, Università Cattolica, 2014), Aix-en-Provence (LAGV 2014), and particularly Klaas Staal and Agustin Casas. A previous version of this research was part of a project circulated with a different title. The usual disclaimer applies.
} 


\section{Introduction}

The conventional premise that high or nearly universal rates of voter participation are desirable (Lijphart, 1997) does not seem to receive widespread support in recent theoretical research. In particular, within a framework where voters have private values and commonly shared values and vote in an instrumental way, Ghosal and Lockwood (2009) prove that a switch from private to common value voting might lead both to lower turnout and to better selection of agents, and Aldashev (2015) shows that lower turnout due to higher ideological mobility of voters actually reduces equilibrium rents by self-interested politicians.

We contribute to this strand of literature by developing a model where voters receive an informative signal about the valence of candidates that may or not match their ideological preferences. As the cost of voting increases, turnout unambiguously decreases, and, more interestingly, the composition of voters changes so that, eventually, only voters for whom the common value signal on candidates' valence matches their private value views will choose to turn out. This implies that the elected candidate's win margin increases in the cost of voting and, above a certain threshold, the valent candidate is elected by a plebiscitary vote.

\section{Theoretical model}

We assume that two candidates $(l, r)$ run for office. The candidate securing the majority of the votes of the electorate in a 'winner-takes-all' race sets the one-dimensional policy $\pi^{x}$, where $x \in\{l, r\}$, based on his ideology.

Voting is voluntary, costly, and driven by two expressive motives (Hamlin and Jennings, 2011): a private value motive (ideology) and a common value motive (valence). Voter $j$ is ideologically attached to candidate $x$ with probability 0.5 , meaning that no candidate enjoys a 
systematic ideological bias. Valence is instead a commonly valued issue linked to imperfectly observed candidates' inner characteristics, as competence or probity (Besley, 2005).

Voters' behavior consists of two stages. First, the relative weight of ideology and valence issues determines whether, conditional on turning out to vote, individuals vote according to ideology or valence. Second, the comparison of the benefits with the costs of voting determines whether people turn out to vote. Each voter $j$ has a set of beliefs $\left\{\iota_{j}, \kappa_{j}\right\}$, with $\iota_{j} \in\{l, r\}$ being the ideological attachment to either of the candidates' policies, and $\kappa_{j} \in\{l, r\}$ voter $j$ 's belief about candidates' valence. Candidate $x$ is valent in state of the world $s^{x} \in\left\{s^{l}, s^{r}\right\}$, with the two states of the world being equally likely ex ante, and voter $j$ receives a signal $\kappa_{j}$ such that $\operatorname{Pr}\left(\kappa_{j}=x \mid s=s^{x}\right)=q>0.5$. The valence signal may or may not match a voter's ideological preference $\iota_{j}$.

Based on their sets of beliefs, voters can be categorized as ideological if the benefit of voting by ideology is larger than the benefit of voting by valence, and conditional on turning out, they vote according to $\mathrm{t}_{\mathrm{j}}$ irrespective of $\kappa_{\mathrm{j}}$, or pragmatic if the benefit of voting by valence is larger than the benefit of voting by ideology, and vote according to $\kappa_{j}$ irrespective of $\iota_{j}$.

As for the turnout decision, the net benefit of turning out to vote $\left(e_{j}\right)$ is:

$$
e_{j}=\left\{\begin{array}{ccc}
{\left[i_{j}+v_{j}\right]-c_{j}} & \text { if } & \iota_{j}=\kappa_{j} \\
\max \left\{i_{j}, v_{j}\right\}-c_{j} & \text { if } & \iota_{j} \neq \kappa_{j}
\end{array}\right.
$$

where $i$ is the benefit of voting by ideology, $v$ is the benefit of voting for the candidate that is believed to be valent, and $c$ is the cost of voting. A voter turns out to vote $\left(t_{j}=1\right)$ if the net benefit is positive:

$$
t_{j}=1\left(e_{j}>0\right)
$$


We hypothesize that $v_{j}=V+\varepsilon_{j}$, where $V$ is a positive parameter, and $\varepsilon$ is independently and uniformly distributed on $[-\sigma, \sigma]$, with $0 \leq \sigma \leq V$, and that $E[\varepsilon \mid i]=0$. As for ideology, $i$ is assumed to be independently and uniformly distributed on $[0, I]$, with $I>V$, and cumulative distribution function $\Phi=\frac{i}{I}$. The voting $\cos t c_{j}$ is allowed to be correlated across voters due to the fact that individuals residing in a jurisdiction face the same or similar conditions.

Figure 1 offers a graphical representation of the forces determining how and whether people vote. Voters are ordered according to the relevance of $i$, with $\Phi$ on the horizontal axis indexing voters' cumulative distribution function. ${ }^{1}$ Assume that $v_{j}$ is constant across voters $(\sigma=0)$, and that $I>2 \mathrm{~V}$, implying that the majority of voters are ideological. ${ }^{2}$ Figure 1 first depicts how people vote. The fraction of voters $\Phi=\frac{V}{I}$ have $i_{j}<V$ and vote pragmatically, while the fraction $1-\frac{V}{I}$ have $i_{j}>V$, and vote ideologically.

As for the turnout decision, voters for whom the valence signal matches their ideological views have benefits from turning out to vote as given by the solid straight line $\mathbf{m}(i+v)$ in Figure 1, while 'no match' voters - for whom valence signals are clashing with ideological views have benefits described by the solid piecewise linear curve $\mathbf{n m}(\max \{i, v\})$. Say that the cost of voting is homogeneous across voters at $c_{j}=c>0$. According to (1) and (2), all voters for whom the benefits from voting ( $\mathbf{m}$ or $\mathbf{n m}$ ) exceed $c$ will turn out, while the others will abstain.

\footnotetext{
${ }^{1}$ The actual shape and position of the cumulative distribution of the ideological value of voting is likely to vary depending on institutions (Revelli, 2016). Here, we take them as given and focus on the role of circumstances determining the cost of voting.

${ }^{2} I=2 \mathrm{~V}$ implies that exactly half the electorate is ideological and half is pragmatic. All graphs in this section are drawn by setting: $V=3 ; I=8 ; q=0.7$.
} 
Consider now the effect of the cost of voting on pragmatic voters' turnout $t(v)$ :

$$
t(v)=\left\{\begin{array}{rll}
\frac{V}{I} & \text { if } & c<V \\
\frac{V}{I}-\frac{c}{2 I} & \text { if } & V<c<2 V \\
0 & \text { if } & c>2 V
\end{array}\right.
$$

As Figure 2 shows, all pragmatic voters $\left(\frac{V}{I}\right)$ turn out when $c<V$, while none of them participates when $c>2 V$ even if the signal matches their ideological views. For $V<c<2 V$, the only pragmatic voters that turn out are those for whom the valence signal matches their ideological views (i.e., are on line $\mathbf{m}$ ), and the total benefits from voting exceed costs: $i_{j}+V>$ c. On the other hand, ideological voters' turnout $t(i)$ declines with the cost of voting according to:

$$
t(i)=\left\{\begin{array}{ccc}
1-\frac{V}{I} & \text { if } & c<V \\
1-\frac{V}{2 I}-\frac{c}{2 I} & \text { if } & V<c<2 V \\
1+\frac{V}{2 I}-\frac{c}{I} & \text { if } & 2 V<c<I \\
\frac{1}{2}+\frac{V}{2 I}-\frac{c}{2 I} & \text { if } & I<c<V+I \\
0 & \text { if } & c>V+I
\end{array}\right.
$$

All ideological voters $\left(1-\frac{V}{I}\right)$ turn out for $c<V$, while a fraction $\frac{1}{2}\left(\frac{c}{I}-\frac{V}{I}\right)$ of them - i.e., those for which the valence signal does not match their ideological stance (line nm) and $i_{j}<c$ - abstain if $V<c<2 V$. For $c>2 V$, some of the 'match' ideological voters abstain too (those that are located close to $\frac{V}{I}$ on line $\mathbf{m}$ in Figure 1, and for whom $i_{j}+V>c$ ). As the cost of voting further increases $(c>I)$, the only voters participating in the election have a valence signal coinciding with their ideological views. Finally, turnout falls to zero for $c>V+I$. 
As a result of (3) and (4), total turnout $t$ is:

$$
t=\left\{\begin{array}{ccc}
1 & \text { if } & c<V \\
1+\frac{V}{2 I}-\frac{c}{I} & \text { if } & V<c<I \\
\frac{1}{2}+\frac{V}{2 I}-\frac{c}{2 I} & \text { if } & I<c<V+I \\
0 & \text { if } & c>V+I
\end{array}\right.
$$

As the cost increases, turnout falls and the process goes on until only ideological voters whose signal about the valence of the candidate matches their political beliefs turn out (for $I<$ $c<V+I)$. Let $t(i)^{m}$ and $t(i)^{n m}$ denote the turnout rates of ideological voters when the signal matches or does not match their ideological views. Given that pragmatic voters turn out at the rate $t(v)$ and always vote according to their valence signals, the probability of electing the valent candidate is:

$$
\begin{aligned}
& P(v)=\frac{\left[t(v)+t(i)^{m}\right] q+t(i)^{n m}(1-q)}{t}
\end{aligned}
$$

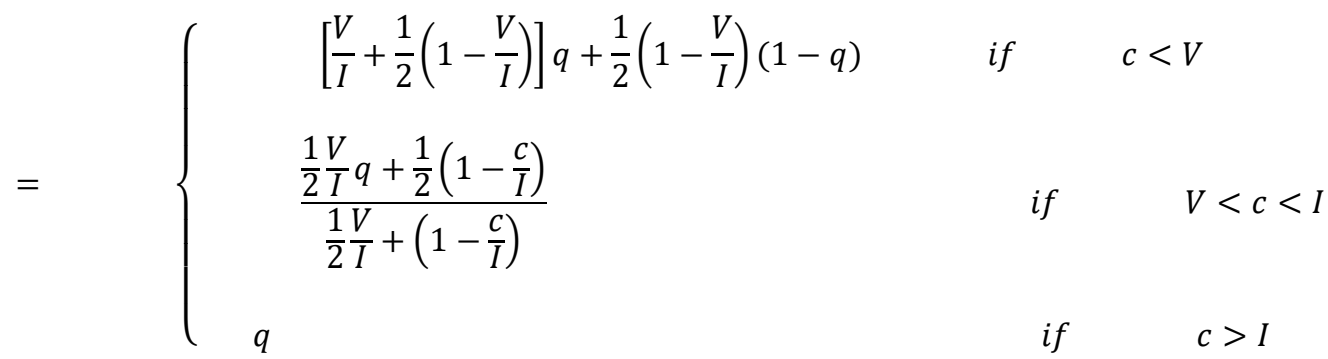

In Figure 3, $P(v)$ falls as the cost of voting surpasses $V$ due to the fact that pragmatic voters for whom the signal collides with their (weak) ideological stances (corresponding to horizontal segment $V g$ in Figure 1) abstain, so that 'good voters' are lost to the democratic process because of the rise in the cost of voting. This result is compatible with the view (Aldashev, 2015) that a decline in turnout might lead to the selection of less valent candidates. For $c>V$, though, the probability of electing the valent candidate increases with $c$. As $c$ rises, the share of 
voters casting their votes according to the correct signal increases relative to the share of ideological voters blindly voting against their signals. $P(v)$ keeps on increasing until cost $I$ is reached, where only ideological voters for whom the valence signal matches their ideological views (corresponding to segment $h[V+I]$ in Figure 1) turn out to vote.

At $c \geq I$, all those who turn out vote according to their valence signal, and $P(v)$ equals $q$. It is easily verified that $P(v)$ at $c<V$ is strictly lower than $q$ if $q>0.5$. Consequently, the probability of electing the valent candidate is maximized when the voting cost is at least as large as $I$. Somewhat unexpectedly, maximization of the chances of electing a valent candidate requires both pragmatic voters and ideological voters whose signal does not match their ideological views to abstain, and only the subgroup of radical voters for whom the common value signal matches their private value views to show up at the polls.

Finally, call $w$ the win margin of the elected candidate, defined as the difference in votes between the two candidates divided by the votes gained by the elected candidate:

$$
w=\left\{\begin{array}{clc}
1-\frac{\frac{1}{2}\left(1-\frac{V}{I}\right)}{\frac{V}{I}+\frac{1}{2}\left(1-\frac{V}{I}\right)} & \text { if } & c<V \\
1-\frac{\left(1-\frac{c}{I}\right)}{\frac{V}{I}+\left(1-\frac{c}{I}\right)} & \text { if } & V<c<I \\
1 & \text { if } & c>\quad I
\end{array}\right.
$$

The win margin of the elected candidate first decreases in $c$. However, the win margin is strictly increasing in $c$ for $c>V$, and equals $100 \%$ when $c>I$. Thus, when only radical ideological voters for whom the valence signal matches their views turn out at the polls, the valent candidate is elected by a plebiscitary vote. 


\section{Concluding remarks}

We have built an expressive voting model where the weight of the ideological content of a policy - say, a high versus a low income tax rate - relative to the valence of candidates determines whether, conditional on turning out to vote, individuals vote according to ideology or valence, and the comparison of the expressive benefits from voting with the cost of voting determines whether people turn out to vote. The model predicts that a higher cost of voting raises the chances of electing the most valent candidate due to a selection mechanisms whereby low turnout elections tend to be characterized by a larger share of voters for whom the common value signal matches their private value views.

Of course, our model does not imply that low voter turnout contests should always be preferable to high voter turnout ones, nor that efforts to raise voters' democratic participation are misplaced. Rather, it suggests that the distribution of the relative strength of ideological versus pragmatic motives in the population of potential voters is a crucial factor in predicting to what extent the actual rate of voters' participation in elections is going to affect the characteristics of the elected officials and the quality of their policies. 


\section{References}

Aldashev, G., 2015. Voter turnout and political rents. Journal of Public Economic Theory 17, $528-552$.

Besley, T., 2005. Political selection. Journal of Economic Perspectives 19, 43-60.

Ghosal, S., Lockwood, B., 2009. Costly voting when both information and preferences differ: Is turnout too high or too low? Social Choice and Welfare 33, 25-50.

Hamlin, A., Jennings, C., 2011. Expressive political behaviour: Foundations, scope and implications. British Journal of Political Science 41, 645-670.

Lijphart, A., 1997. Unequal participation: Democracy's unresolved dilemma. American Political Science Review 91, 1-14.

Revelli, F., 2016. Tax limits and local elections. Public Choice 166, 53-68. 
Figure 1 Ideology and valence in voting

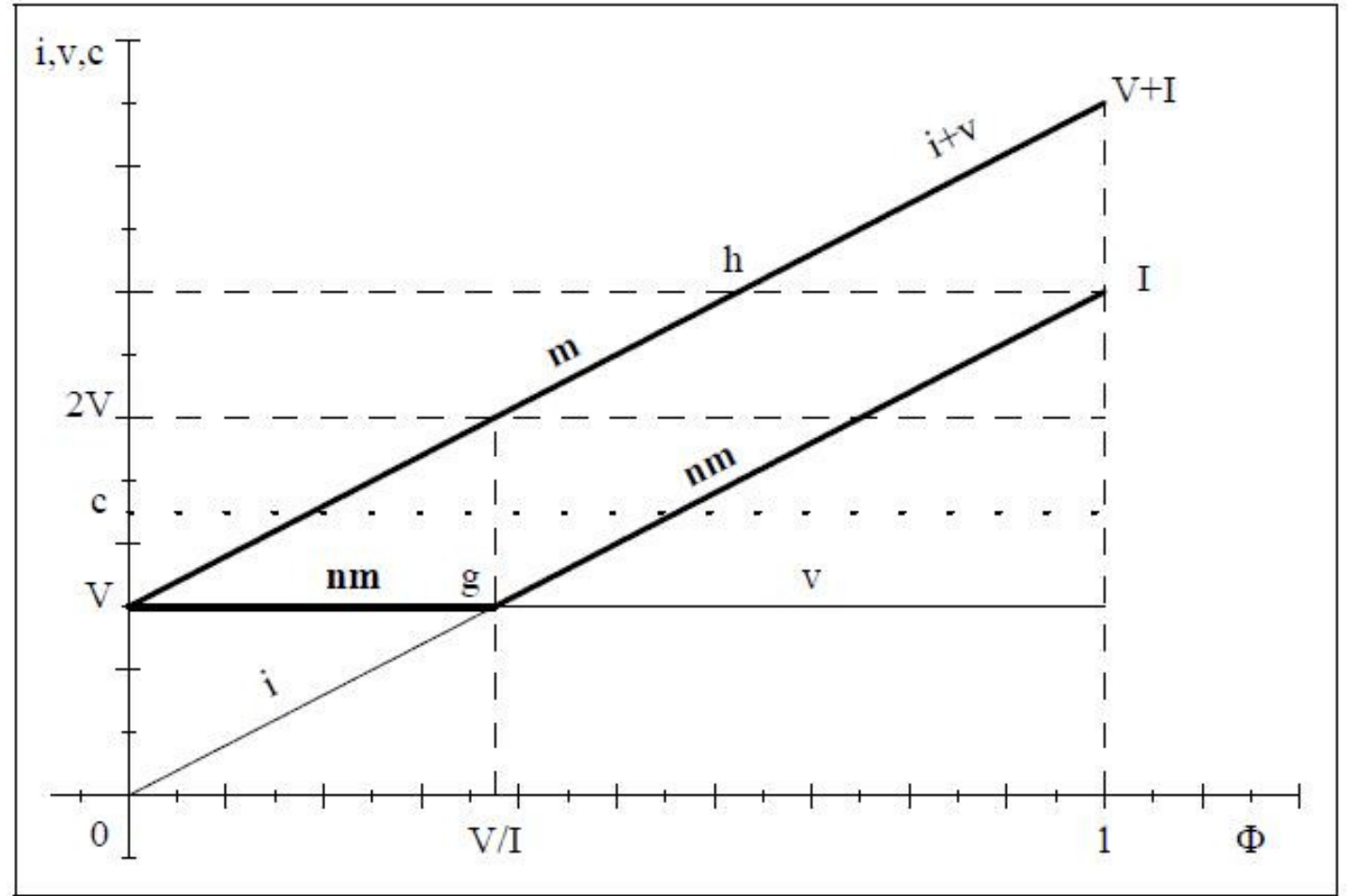


Figure 2 Turnout

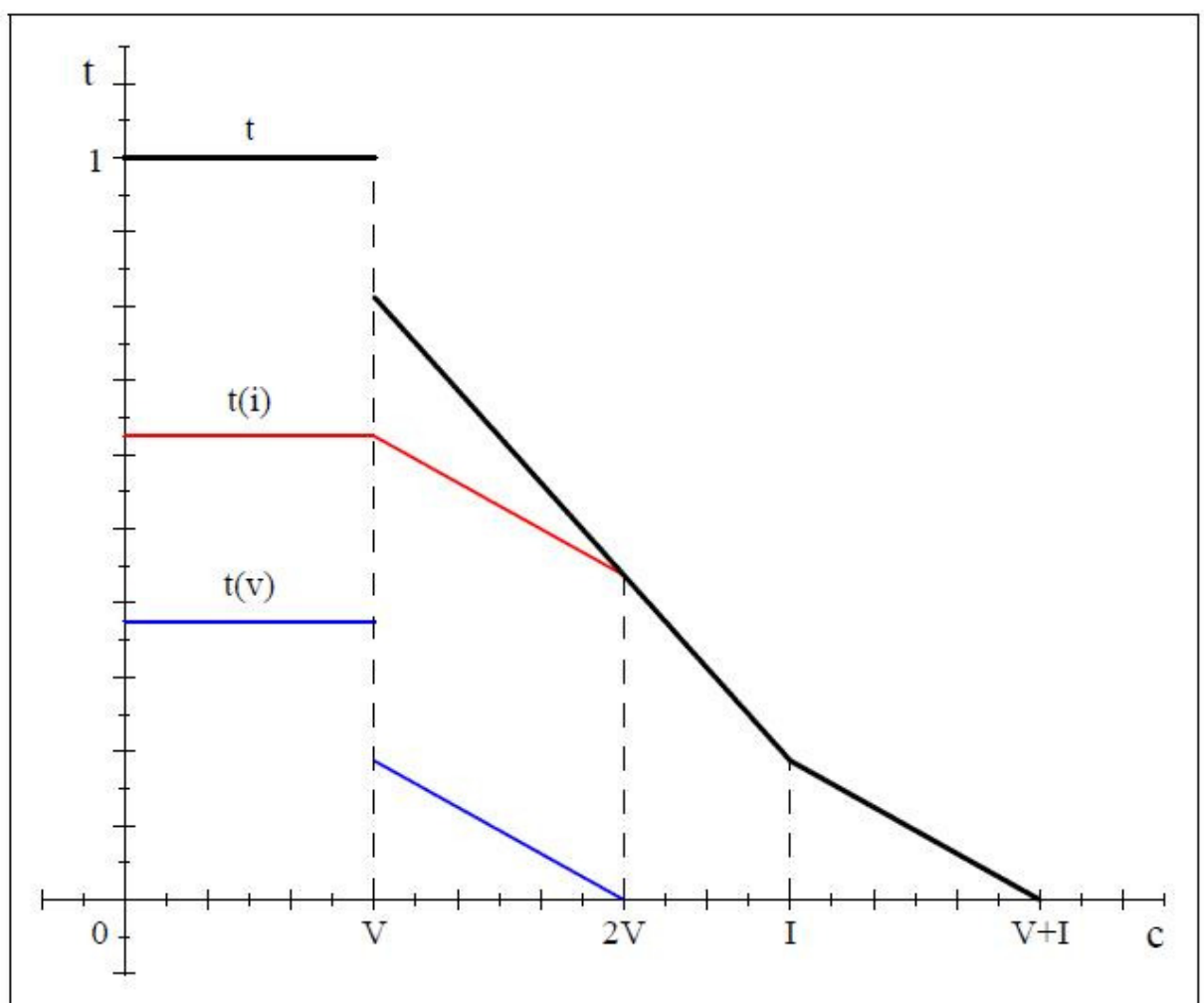


Figure 3 Candidate valence and the cost of voting

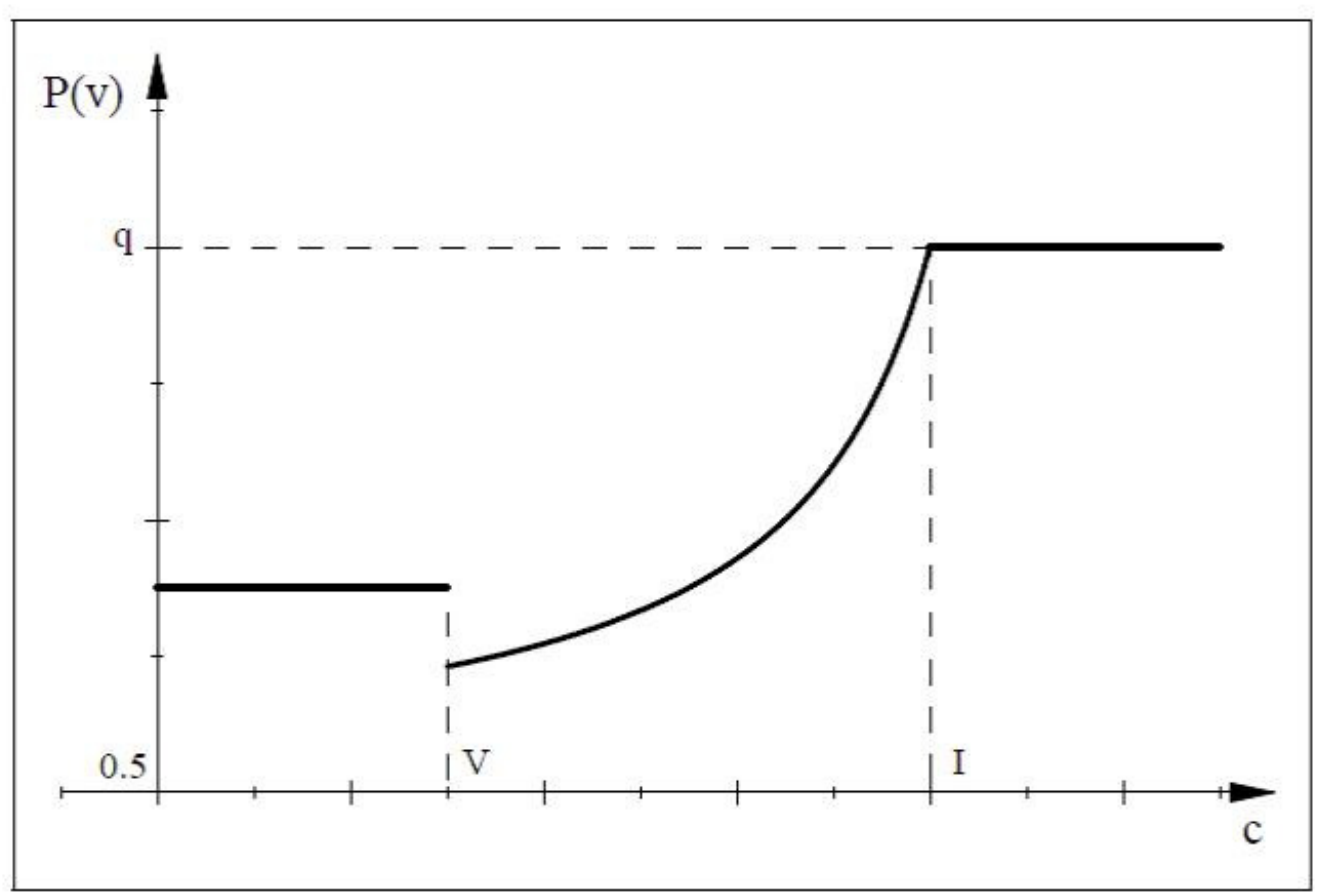

